\title{
Prepared and Characteristics of ZnO:YAG/Silicon Nanostructure Diodes Prepared by Ultrasonic Spraying
}

\author{
Chih-Hung Hsu, Lung-Chien Chen, and Jia-Ren Wu \\ Department of Electro-Optical Engineering, National Taipei University of Technology, No. 1, Section 3, Chung-Hsiao E. Road, \\ Taipei 106, Taiwan \\ Correspondence should be addressed to Lung-Chien Chen; ocean@ntut.edu.tw
}

Received 5 February 2014; Revised 2 May 2014; Accepted 3 May 2014; Published 26 May 2014

Academic Editor: Chao-Rong Chen

Copyright (C) 2014 Chih-Hung Hsu et al. This is an open access article distributed under the Creative Commons Attribution License, which permits unrestricted use, distribution, and reproduction in any medium, provided the original work is properly cited.

This work presents a novel white light source. An yttrium aluminum garnet (YAG) phosphor incorporated zinc oxide (ZnO) (ZnO:YAG) film is deposited on a silicon substrate by ultrasonic spray pyrolysis to form a nanostructure diode. A nanoflower consisting of a hexagonal nanopetal is formed on the surfaces of the silicon substrate. A white broad band at the room temperature photoluminescence ranging from 420 to $650 \mathrm{~nm}$ for the $\mathrm{ZnO}$ :YAG/silicon nanostructure diode was observed. The white broad band consists of the emissions of defect level transition of the $\mathrm{ZnO}$ film and the ${ }^{5} \mathrm{D}_{4}$ level to the ${ }^{7} \mathrm{~F}_{6}$ and ${ }^{7} \mathrm{~F}_{5}$ level transitions of Ce ${ }^{3+}$ ions.

\section{Introduction}

Solid state lighting is the next generation light source, owing to its potential luminescence efficiency. The white light source of the solid state lighting consists of multiple emissions in visible. For example, GaN-based white light-emitting diode (LED) is the most widely used solid state light source, which included a blue LED chip and a yellow phosphor coating. The advantages of the GaN-based LED white light source are long lifetime, high energy efficiency, small size, ability to produce color light directly without filtering, and integration with other semiconductor electronic elements [1-6]. However, the disadvantages of the GaN-based LED white light source are high manufacturing cost and low yield rate due to the expensive growth technology and source materials of metalorganic chemical vapor deposition and the Ga-N bonding mechanism, respectively.

Therefore, it is imperative to develop a novel and lowcost white light device for light source. $\mathrm{ZnO}$ is commonly used as a material for optical device applications in the UV range owing to its wide direct band gap $(3.37 \mathrm{eV})$ [710]. Several articles about $\mathrm{n}-\mathrm{ZnO} / \mathrm{p}-\mathrm{GaN}$ heterostructure LED were reported [11-13]. However, that is a UV range structure, and no optical characteristics were demonstrated.
In this work, an yttrium aluminum garnet (YAG) phosphor incorporated $\mathrm{ZnO}$ film is deposited on silicon substrate by ultrasonic spray pyrolysis to form a ZnO:YAG/silicon nanostructure diode. Additionally, the crystallinity of YAG phosphor incorporated into $\mathrm{ZnO}$ films is studied using X-ray diffraction (XRD) analysis. The optoelectronic characteristics of the $\mathrm{ZnO}: Y A G / S i$ nanostructure diode are also studied.

\section{Experimental Details}

$\mathrm{ZnO}$ incorporated yttrium aluminum garnet (YAG) phosphor film was deposited by ultrasonic spray pyrolysis on $\mathrm{p}$ type silicon substrates at atmospheric pressure in nitrogen $\left(\mathrm{N}_{2}\right)$ gas, at a flow rate of $100 \mathrm{sccm}$ for $20-60 \mathrm{~min}$. The $\mathrm{ZnO}$ incorporated YAG phosphor film (YAG phosphor at 0, 1, 5, and 10 at wt\%) (phosphor: NYAG4156, INTEMATIX, US) was produced by spraying aqueous solutions. Zinc acetate, ammonium acetate, and YAG phosphor were mixed in D.I. water to prepare the precursor solution. The solutions were stirred at room temperature for $1 \mathrm{~h}$ and then moved into a commercial ultrasonic nebulizer which makes the solutions be aerosol which contains TAG phosphor. The aerosol was transported to the substrate by high purity nitrogen gas and the substrate was kept at $500^{\circ} \mathrm{C}$. The YAG phosphor 


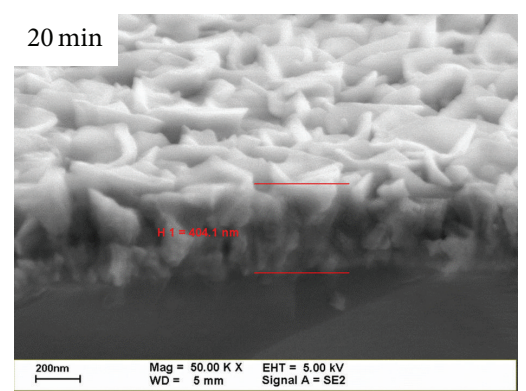

(a)

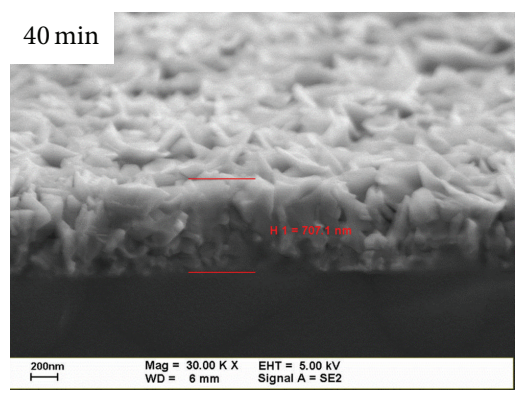

(b)

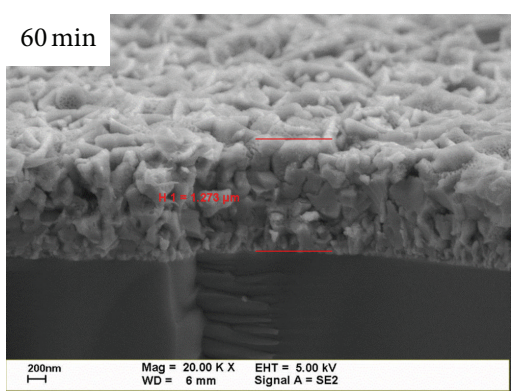

(c)

FIGURE 1: FESEM micrographs of the ZnO:YAG films (YAG phosphor at $5 \mathrm{wt} \%$ ) with various deposition times: (a) 20 min, (b) 40 min, and (c) $60 \mathrm{~min}$.

was incorporated in the film when the deposition of $\mathrm{ZnO}$ occurs. Single crystalline boron-doped p-type silicon with resistivity of $10 \Omega-\mathrm{cm}$ was used as the substrate, which was etched with $\mathrm{HCl}$ for $5 \mathrm{~min}$ before deposition. An aerosol of the precursor solution was then generated using a commercial ultrasonic nebulizer. $\mathrm{Ag} / \mathrm{Ni}$ electrodes were formed by evaporation onto both the surfaces of the $\mathrm{ZnO}$ :YAG layer and the silicon subtract, to complete the nanostructure diodes. Next, the morphology of film was studied by field emission scanning electron microscope (FESEM). The crystallinity was investigated by X-ray diffraction (XRD) using a rotating anode Rigaku X-ray diffractometer with $\mathrm{Cu}-\mathrm{K} \alpha_{1}$ radiation at a wavelength of $1.54 \AA$, where the radiation was generated at $45 \mathrm{kV}$ and $40 \mathrm{~mA}$. Additionally, photoluminescence (PL) was measured at room temperature (RT). The excitation source for photoluminescence was a frequency-quadrupled Nd:YAG laser, which emitted $266 \mathrm{~nm}, 6 \mathrm{~ns}$ pulses at a $5 \mathrm{~Hz}$ repetition rate. The current-voltage $(I-V)$ characteristics were measured using a Keithley 2420 programmable SourceMeter. Hall measurement was employed to study the electrical properties of the $\mathrm{ZnO}$ films with different concentrations of incorporated YAG which were deposited on glass substrate.

\section{Results and Discussion}

Figure 1 shows the FESEM micrographs of the ZnO:YAG (YAG phosphor at $5 \mathrm{wt} \%$ ) films with various deposition times. The micrographs indicate that nanoflower consists of hexagonal nanopetal on the surface of the films, as shown in Figure 1. The nanoflower sizes were approximately $400 \mathrm{~nm}$ and the size of nanoflower almost has no changes with deposition time increasing. The average deposition rate is about $20 \mathrm{~nm} / \mathrm{min}$. The origin of the hexagonal nanoflower may contribute to decomposition and random nucleation of solution precursor leading to the formation of threedimensional $\mathrm{ZnO}$ nuclei $[7,14,15]$. As the growth proceeds, the growth direction is longitudinal. However, as the growth process is terminated, the three-dimensional growth becomes two-dimensional growth owing to the reduction of the source and the aggregation of the residue precursor, subsequently leading to formation of the hexagonal nanopetal on the surface of the substrate $[14,15]$.

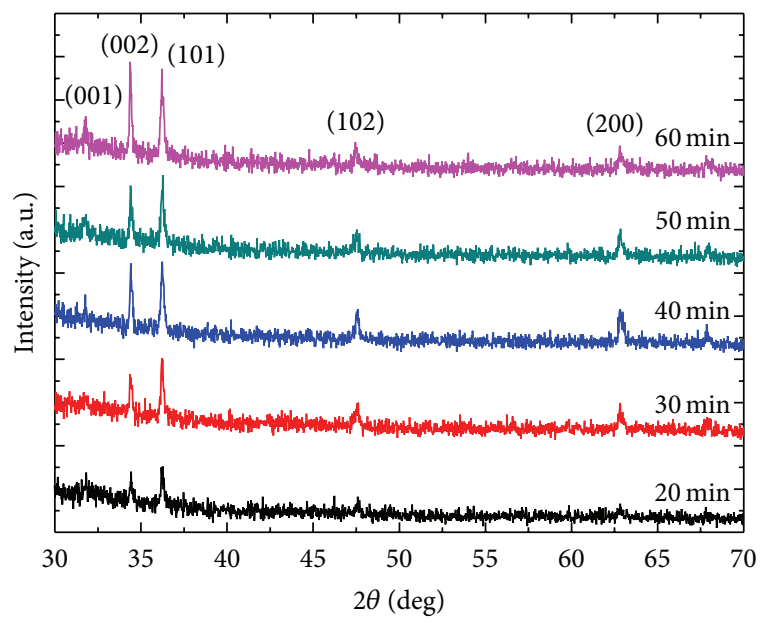

Figure 2: X-ray diffraction patterns of the ZnO:YAG films with various deposition times.

Figure 2 shows a typical X-ray diffraction (XRD) pattern of $\mathrm{ZnO}$ film incorporated YAG phosphor deposited on a sapphire substrate prepared by the ultrasonic spraying pyrolysis method. Three dominant diffraction peaks, that is, $\mathrm{ZnO}(100)\left(2 \theta=31.79^{\circ}\right), \mathrm{ZnO}(002)\left(2 \theta=34.37^{\circ}\right)$, and $\mathrm{ZnO}(101)\left(2 \theta=36.21^{\circ}\right)$, are observed in the range from 30 to $45^{\circ}$. The film demonstrates a polycrystalline structure. The sample deposited for $20 \mathrm{~min}$ has the maximum $\mathrm{ZnO}$ (101) diffraction peak height. As the deposition time increase exceeds $40 \mathrm{~min}$, the intensity in $\mathrm{ZnO}$ (002) diffraction peaks becomes higher than the intensity in $\mathrm{ZnO}$ (101) diffraction peaks. This may contribute to the fact that the grain with orientation of (002) is dominant. In order to attain the detailed structure information, the grain size $G$ along with the $c$-axis was calculated according to Scherrer's equation [16]:

$$
G=\frac{0.9 \lambda}{\beta \cos \theta},
$$

where $G, \lambda, \beta$, and $\theta$ denote the grain size, the X-ray wavelength, the full width at half maximum (FWHM) in radians, and the Bragg angle of (002) or (101) peak, respectively. The grain sizes for the samples deposited with 20, 30, 40, 


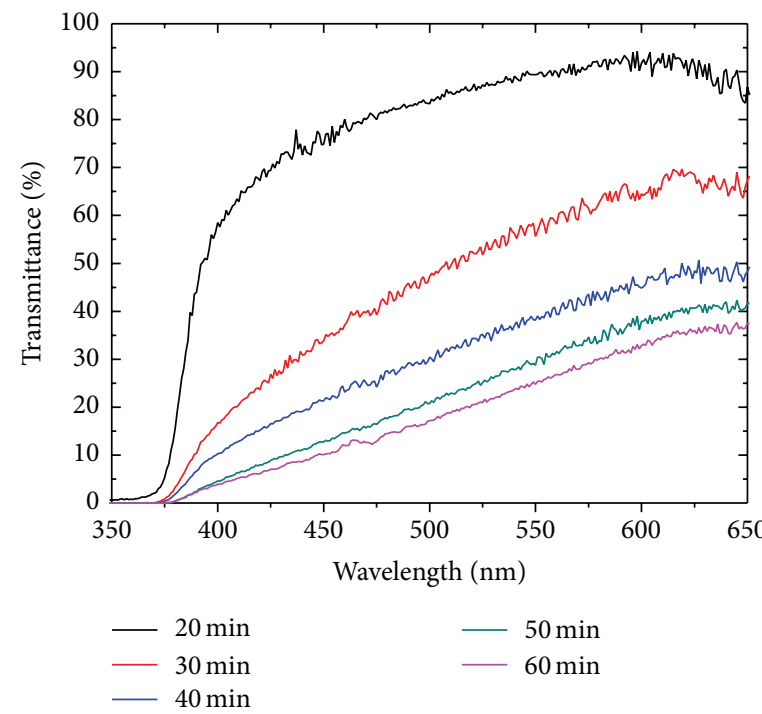

(a)

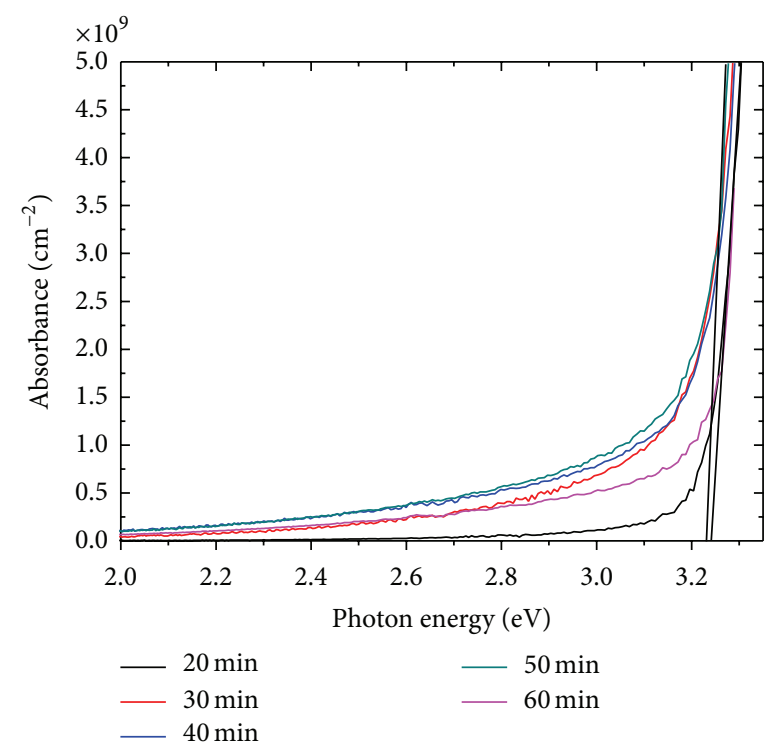

(b)

Figure 3: (a) Transmittance spectra of the ZnO:YAG films deposited for various times. (b) Relationship between the square of the absorbance and photon energy for the ZnO:YAG films.

50 , and $60 \mathrm{~min}$ are $25.97,32.14,36.13,39.78$, and $46.18 \mathrm{~nm}$, respectively. Therefore, the crystallinity of the samples with longer deposition time is better.

Figure 3(a) plots the transmittance spectra of the YAG incorporated $\mathrm{ZnO}$ films deposited for various times, and Figure 3(b) shows the results of the absorption measurements for the YAG incorporated $\mathrm{ZnO}$ films. It can be seen from Figures 3(a) and 3(b) that, as the deposition time increases, the transmittance decreases due to the thickness of the YAG incorporated $\mathrm{ZnO}$ increasing, and the absorbance edge keep almost in $3.15 \mathrm{eV}$. Typically, the band gap of $\mathrm{ZnO}$ film is around $3.37 \mathrm{eV}$ corresponding to the absorption edge at $370 \mathrm{~nm}$ [14]. The red shift may be attributed to the defects in the YAG incorporated $\mathrm{ZnO}$ film $[8,17]$.

Figure 4 presents the room temperature (RT) PL spectra of the $\mathrm{ZnO}$ :YAG (YAG phosphor at $5 \mathrm{wt} \%$ ) deposited for $60 \mathrm{~min}$. The inset shows the photoexcited luminescent photographs. According to Figure 4, the RT PL spectrum of the YAG incorporated $\mathrm{ZnO}$ reveals one peak, denoted as peak $\mathrm{A}$, that is, at $\sim 3.27 \mathrm{eV}(382 \mathrm{~nm})$, and a broad band included four weak peaks, denoted as peaks $\mathrm{B}, \mathrm{C}$, and $\mathrm{D}$ at $2.71 \mathrm{eV}(456 \mathrm{~nm})$, $2.56 \mathrm{eV}(484 \mathrm{~nm})$, and $2.28 \mathrm{eV}(544 \mathrm{~nm})$, respectively. Peak A has the shortest wavelength and, therefore, is interpreted as being associated with free-exciton (FE) or band-to-band (B-B) recombination in the $\mathrm{ZnO}$. Additionally, its position is reasonably close to that of the band gap of $\mathrm{ZnO}$ at $\mathrm{RT}$, which is $\sim 3.285 \mathrm{eV}(377.5 \mathrm{~nm})[8-10,15,17,18]$. Peak B may be attributed to the band-to-deep level transition in the $\mathrm{ZnO}$ film. Peaks $\mathrm{C}$ and $\mathrm{D}$ may correspond to the ${ }^{5} \mathrm{D}_{4}$ level to the ${ }^{7} \mathrm{~F}_{6}$ and ${ }^{7} \mathrm{~F}_{5}$ level transitions of $\mathrm{Ce}^{3+}$ ions, respectively [19-21]. The color of photoluminescence is nearly white, as shown in Figure 5. The white light may contribute to the wide emission band ranging from 420 to $650 \mathrm{~nm}$. Figure 5 shows

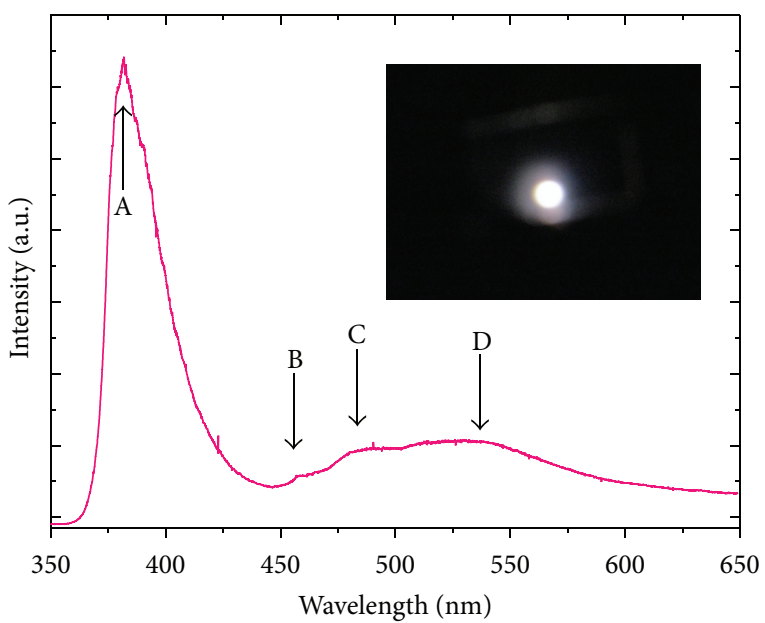

FIgURE 4: RT PL spectra of ZnO:YAG phosphor (YAG phosphor at $5 \mathrm{wt} \%)$ on silicon substrate. The inset shows the photoexcited luminescent photographs.

the PL spectra of the ZnO:YAG thin films with different incorporated concentration at the RT. The intensity of all the peaks increases when the incorporated concentration increases. The chromaticity coordinates of the $\mathrm{ZnO}: \mathrm{YAG}$ films at 1,5 , and $10 \mathrm{wt} \%$ on $\mathrm{Si}$ substrate are presented in the CIE chromaticity diagram, as shown in Figure 6. With the increasing incorporated concentration of YAG, the chromaticity coordinates move in white light area from $x=$ $0.2786, y=0.3417$ (CCT $=7958)$ for the sample at $1 \mathrm{wt} \%$ to $x=0.2476, y=0.3665(\mathrm{CCT}=9328)$ for the sample at $10 \mathrm{wt} \%$. Therefore, the $\mathrm{ZnO}$ :YAG film on Si substrate is suitable for solid state lighting because it has a stable white 


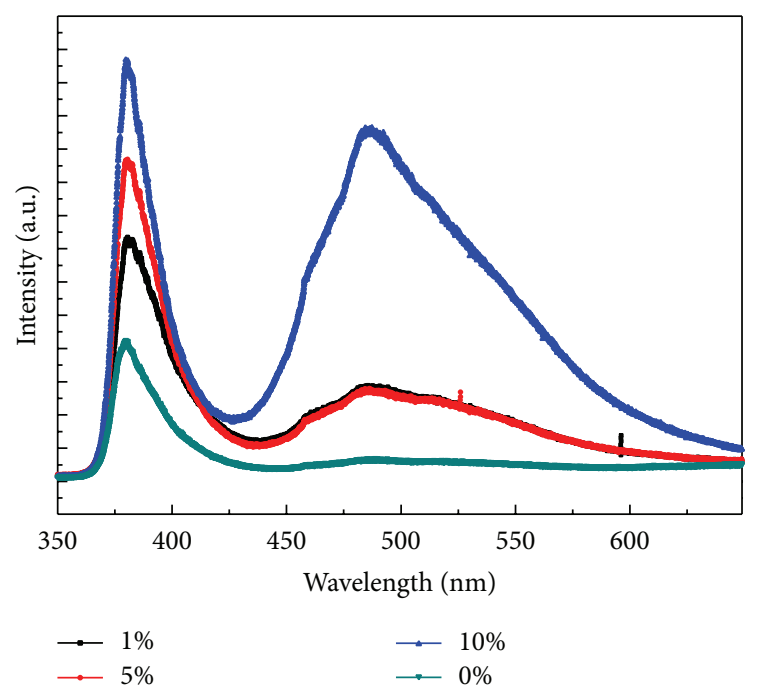

Figure 5: PL spectra of the $\mathrm{ZnO}$ thin films with different concentrations of incorporated YAG at room temperature.

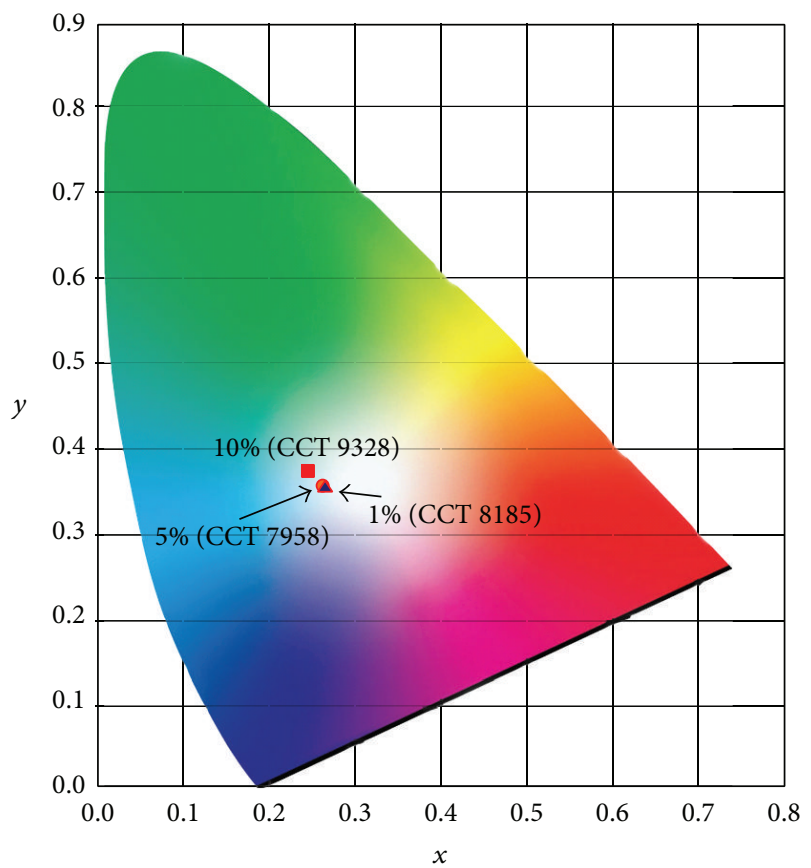

FIGURE 6: Chromaticity coordinates of the ZnO:YAG films at 1, 5, and $10 \mathrm{wt} \%$ on Si substrate.

light color when the incorporated concentration is in the range of $1-5 \mathrm{wt} \%$.

Figure 7 shows the resistivity and the mobility as a function of the different concentrations for phosphor doped $\mathrm{ZnO}$. In undoped $\mathrm{ZnO}$ thin films, the resistivity and the mobility were $33 \Omega-\mathrm{cm}$ and $1.7 \mathrm{~cm}^{2} / \mathrm{V} \cdot \mathrm{s}$, respectively. When phosphor doped $\mathrm{ZnO}$ at $1 \mathrm{wt} \%$, the resistivity increases, phosphor doped concentration up to 5 and $10 \mathrm{wt} \%$, and then it increases again. On the contrary, the mobility decreases with increasing the doped concentration. The changes in

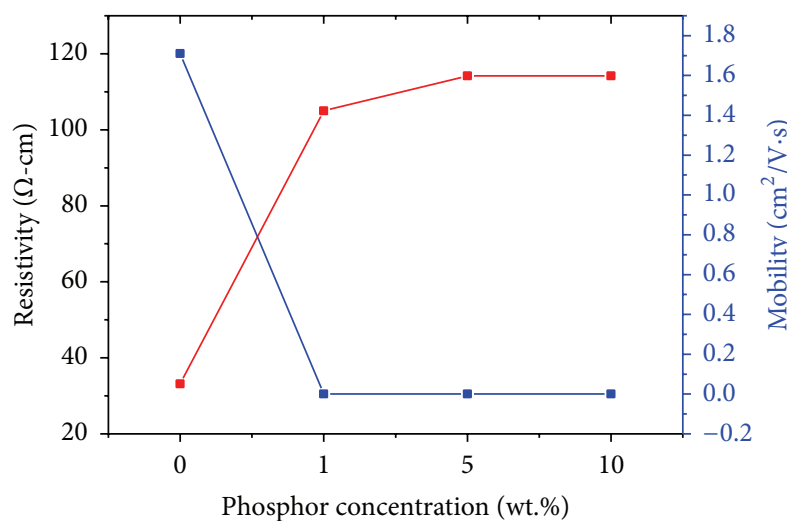

FIGURE 7: Resistivity and mobility of the $\mathrm{ZnO}$ thin films with different concentrations of incorporated YAG deposited on glass substrate.

electrical properties of $\mathrm{ZnO}$ film for the defects increase caused by the doping of the phosphor.

Figure 8(a) plots typical $I-V$ characteristics of the YAG phosphor incorporated $\mathrm{ZnO}$ /silicon heterostructure diodes at room temperature. The inset presents the cross-section of the completed structure. Figure $8(\mathrm{~b})$ plots the currentvoltage $(I-V)$ of the $\mathrm{Ni} / \mathrm{Ag} / \mathrm{ZnO}: \mathrm{YAG}$ and $\mathrm{Ni} / \mathrm{Ag} / \mathrm{p}-\mathrm{Si}$ padto-pad structures, to check for ohmic characteristics and to optimize the performance of the devices. The diode has a turn-on forward bias of $\sim 5 \mathrm{~V}$. The forward bias is high because the ohmic contact condition is not optimized yet. Diode $I-V$ characteristics can be expressed by the Shockley equation:

$$
I=I_{0}\left[\exp \left(\frac{q V}{n K T}\right)-1\right]
$$

where $I_{0}$ is the saturation current density and $n$ is the ideality factor. Equation (2) gives an ideality factor $n$ and saturation current $I_{0}$ of 1.56 and $1.89 \mathrm{nA}$, respectively, indicating that when a diffusion current flows in the reverse direction, the reverse leakage current prior to breakdown is around $10^{-5} \mathrm{~A}$. The breakdown voltage is soft and as high as around $-5 \mathrm{~V}$.

\section{Conclusions}

In summary, an yttrium aluminum garnet (YAG) phosphor incorporated zinc oxide ( $\mathrm{ZnO})$ ( $\mathrm{ZnO}: \mathrm{YAG})$ film has deposited on a silicon substrate by ultrasonic spray pyrolysis. A nanoflower consisting of a hexagonal nanopetal is formed on the surfaces of the silicon substrate, and the sizes of the nanoflower are approximately $400 \mathrm{~nm}$. The $\mathrm{ZnO}: \mathrm{YAG} /$ silicon nanostructure diode has a turn-on forward bias of $\sim 5 \mathrm{~V}$. The reverse leakage current prior to breakdown is around $10^{-5} \mathrm{~A}$. The breakdown voltage is soft and as high as around $-5 \mathrm{~V}$. A white broad band at room temperature photoluminescence ranging from 420 to $650 \mathrm{~nm}$ was observed. The white broad band consists of the emissions of defect level transition of the $\mathrm{ZnO}$ film and the ${ }^{5} \mathrm{D}_{4}$ level to the ${ }^{7} \mathrm{~F}_{6}$ and ${ }^{7} \mathrm{~F}_{5}$ level transitions of $\mathrm{Ce}^{3+}$ ions. 


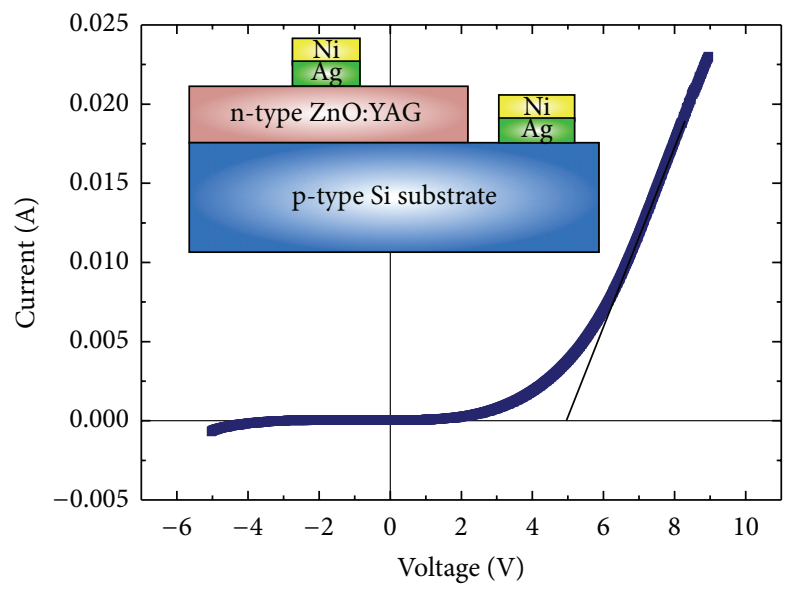

(a)

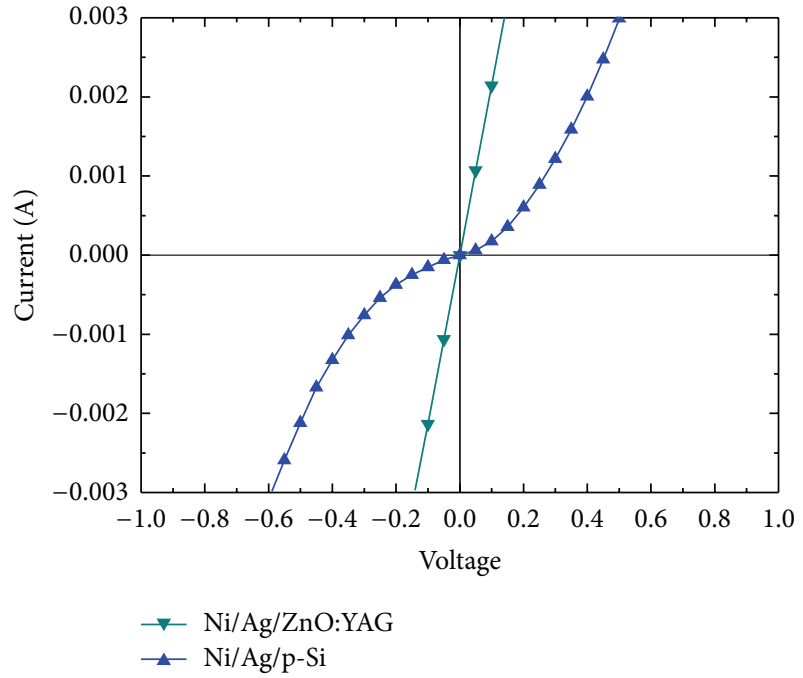

(b)

FIGURE 8: (a) Typical current-voltage characteristics of ZnO:YAG/silicon nanostructure diode. The inset shows the cross-section of the completed structure of the ZnO:YAG/silicon nanostructure diode. (b) The current-voltage $(I-V)$ characteristics of Ni/Ag/ZnO:YAG and $\mathrm{Ni} / \mathrm{Ag} / \mathrm{p}-\mathrm{Si}$ junctions, respectively.

\section{Conflict of Interests}

The authors declare that there is no conflict of interests regarding the publication of this paper.

\section{Acknowledgment}

Financial support of this work was provided by the National Science Council of the Republic of China under Contract no. NSC 101-2221-E-027-054.

\section{References}

[1] Y. C. Shen, J. J. Wierer, M. R. Krames et al., "Optical cavity effects in InGaN/GaN quantum-well-heterostructure flip-chip light-emitting diodes," Applied Physics Letters, vol. 82, no. 14, pp. 2221-2223, 2003.

[2] T. Mukai, M. Yamada, and S. Nakamura, "Characteristics of InGaN-based UV/blue/green/amber/red light-emitting diodes," Japanese Journal of Applied Physics, Part 1: Regular Papers and Short Notes and Review Papers, vol. 38, no. 7 B, pp. 3976-3981, 1999.

[3] L.-C. Chen and Y.-L. Huang, "High reliability GaN-based lightemitting diodes with photo-enhanced wet etching," Solid-State Electronics, vol. 48, no. 7, pp. 1239-1242, 2004.

[4] L.-C. Chen, J.-B. Huang, P.-J. Cheng, and L.-S. Hong, "InGaN blue light-emitting diodes with $\mathrm{ZnO}$ nucleation layers prepared by the sol-gel method," Semiconductor Science and Technology, vol. 22, no. 10, pp. 1178-1182, 2007.

[5] L.-C. Chen and Y.-M. Ho, "Ag and zinc oxide-doped indium oxide ohmic contacts to p-type GaN for flip-chip LED applications," Journal of Physics D: Applied Physics, vol. 40, no. 21, pp. 6514-6517, 2007.

[6] L.-C. Chen, C.-H. Tien, and C.-S. Mu, "Effects of spin-polarized injection and photoionization of $\mathrm{MnZnO}$ film on GaN-based lightemitting diodes," Optics Express, vol. 18, no. 3, pp. 2302 2308, 2010.

[7] S. C. Su, Y. M. Lu, Z. Z. Zhang et al., "The optical properties of $\mathrm{ZnO} / \mathrm{ZnMgO}$ single quantum well grown by P-MBE," Applied Surface Science, vol. 254, no. 22, pp. 7303-7305, 2008.

[8] X. H. Wang, B. Yao, D. Z. Shen et al., "Optical properties of p-type $\mathrm{ZnO}$ doped by lithium and nitrogen," Solid State Communications, vol. 141, no. 11, pp. 600-604, 2007.

[9] X. H. Zhang, S. J. Chua, A. M. Yong et al., "Exciton radiative lifetime in $\mathrm{ZnO}$ nanorods fabricated by vapor phase transport method," Applied Physics Letters, vol. 90, no. 1, Article ID 013107, 2007.

[10] Y. Danhara, T. Hirai, Y. Harada, and N. Ohno, "Exciton luminescence of $\mathrm{ZnO}$ fine particles," Physica Status Solidi (C) Current Topics in Solid State Physics, vol. 3, no. 10, pp. 35653568, 2006.

[11] W. C. Li, H. L. Tsai, H. C. Chen et al., "Structural investigation of $\mathrm{n}-\mathrm{ZnO} / \mathrm{p}-\mathrm{GaN}$ ultraviolet light-emitting diodes grown by atomic layer deposition," Functional Materials Letters, vol. 4, no. 3, pp. 221-224, 2011.

[12] S. K. Jha, O. Kutsay, I. Bello, and S. T. Lee, "ZnO nanorod based low turn-on voltage LEDs with wide electroluminescence spectra," Journal of Luminescence, vol. 133, pp. 222-225, 2013.

[13] H.-Y. Shih, S.-H. Cheng, J.-K. Lian, T.-Y. Lin, and Y.-F. Chen, "Light-emitting devices with tunable color from $\mathrm{ZnO}$ nanorods grown on InGaN/GaN multiple quantum wells," Optics Express, vol. 20, no. 6, pp. A270-A277, 2012.

[14] H.-W. Sun, G.-Y. Kim, Y.-S. Jung, W.-K. Choi, and D. Byun, "Growth and properties of $\mathrm{ZnO}$ nanoblade and nanoflower prepared by ultrasonic pyrolysis," Journal of Applied Physics, vol. 97, no. 4, Article ID 044305, 2005.

[15] L.-C. Chen and C.-C. Huang, "Optoelectronic characteristics of YAG phosphor-incorporated $\mathrm{ZnO}$ films deposited by ultrasonic spray pyrolysis," Nanoscale Research Letters, vol. 7, article 627, 2012. 
[16] C. H. Hsu, L. C. Chen, and X. Zhang, "Effect of the Cu source on optical properties of $\mathrm{CuZnO}$ films deposited by ultrasonic spraying," Materials, vol. 7, pp. 1261-1270, 2014.

[17] X.-Y. Li, H.-J. Li, Z.-J. Wang et al., "Effect of substrate temperature on the structural and optical properties of $\mathrm{ZnO}$ and $\mathrm{Al}$ doped $\mathrm{ZnO}$ thin films prepared by dc magnetron sputtering," Optics Communications, vol. 282, no. 2, pp. 247-252, 2009.

[18] J.-H. Lim, C.-K. Kong, K.-K. Kim, I.-K. Park, D.-K. Hwang, and S.-J. Park, "UV electroluminescence emission from $\mathrm{ZnO}$ lightemitting diodes grown by high-temperature radiofrequency sputtering," Advanced Materials, vol. 18, no. 20, pp. 2720-2724, 2006.

[19] G. Phaomei, R. S. Ningthoujam, W. R. Singh et al., "Luminescence switching behavior through redox reaction in $\mathrm{Ce}^{3+}$ codoped $\mathrm{LaPO}_{4}: \mathrm{Tb}^{3+}$ nanorods: re-dispersible and polymer film," Dalton Transactions, vol. 40, no. 43, pp. 11571-11580, 2011.

[20] Y. Zhang, L. Li, X. Zhang, and Q. Xi, “Temperature effects on photoluminescence of YAG: $\mathrm{Ce}^{3+}$ phosphor and performance in white light-emitting diodes," Journal of Rare Earths, vol. 26, no. 3, pp. 446-449, 2008.

[21] A. Lakshmanan, R. S. Kumar, V. Sivakumar, P. C. Thomas, and M. T. Jose, "Synthesis, photoluminescence and thermal quenching of YAG:Ce phosphor for white light emitting diodes," Indian Journal of Pure and Applied Physics, vol. 49, no. 5, pp. 303-307, 2011. 

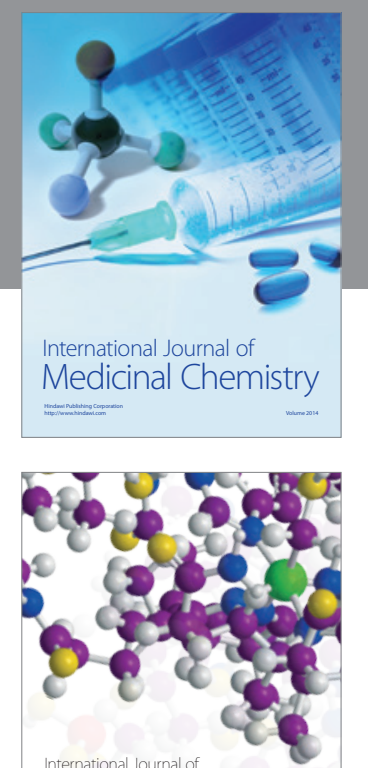

\section{Carbohydrate} Chemistry

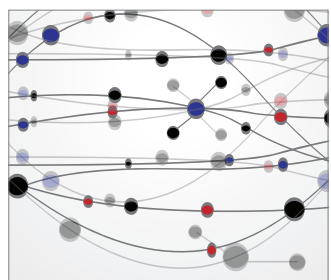

The Scientific World Journal
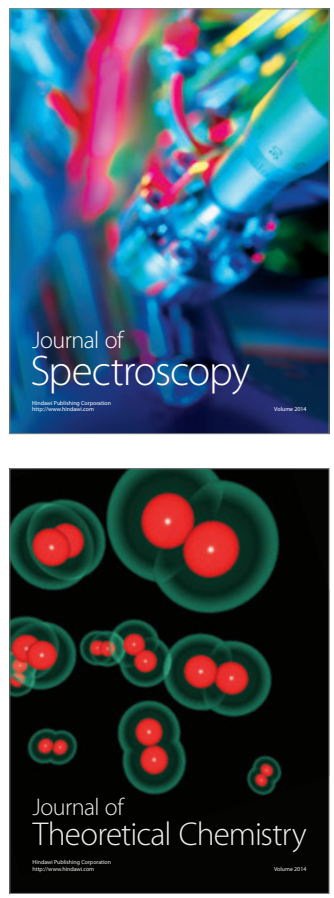
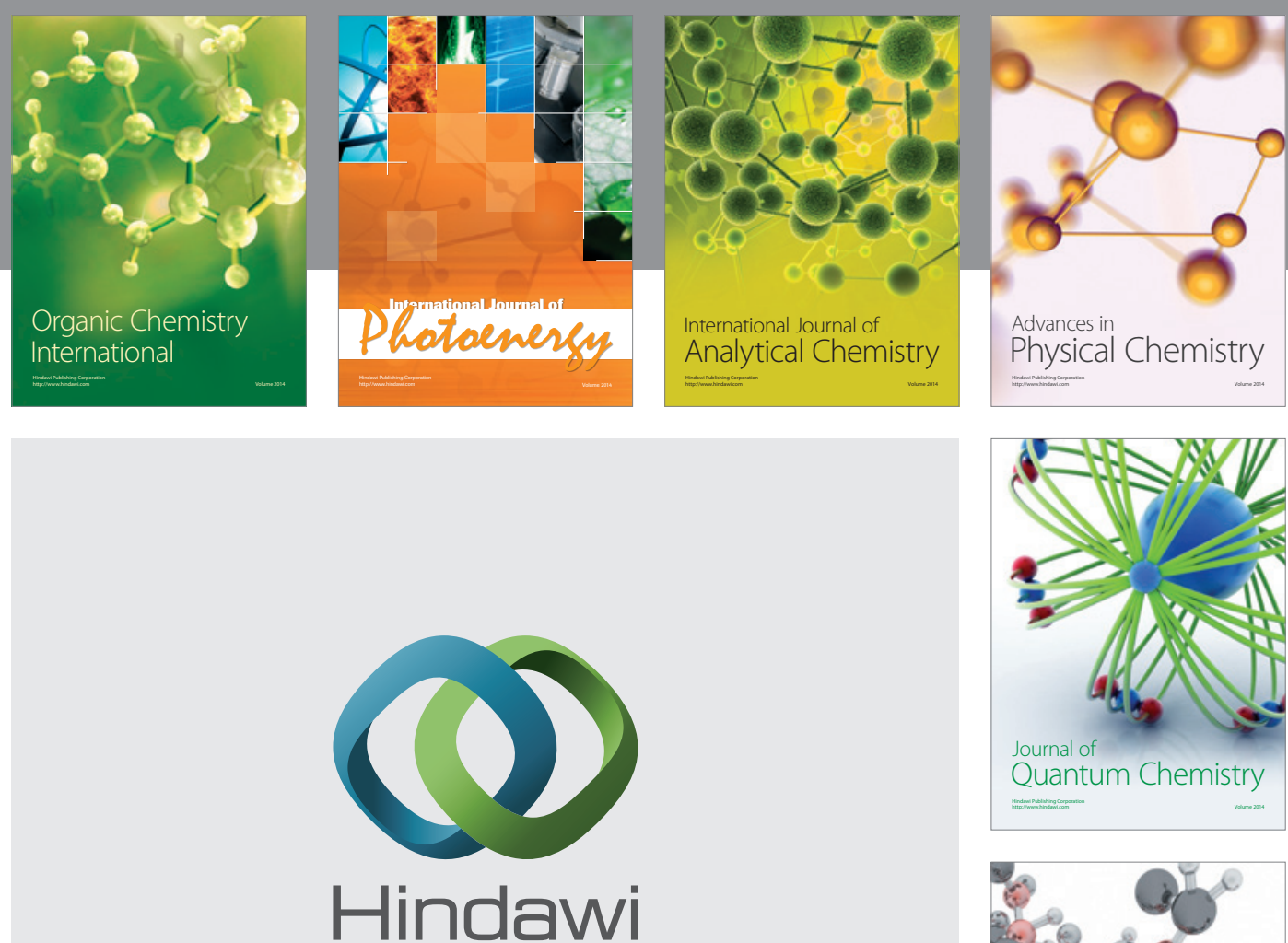

Submit your manuscripts at

http://www.hindawi.com

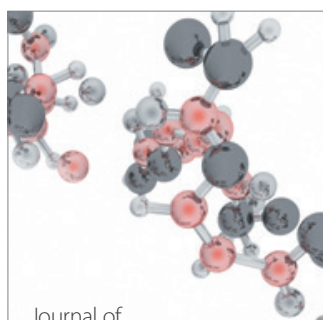

Analytical Methods

in Chemistry

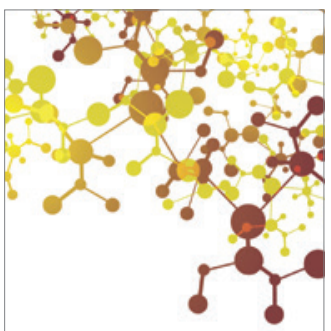

Journal of

Applied Chemistry

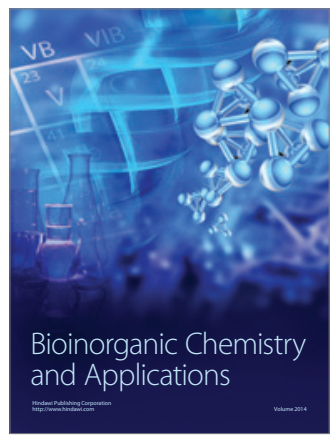

Inorganic Chemistry
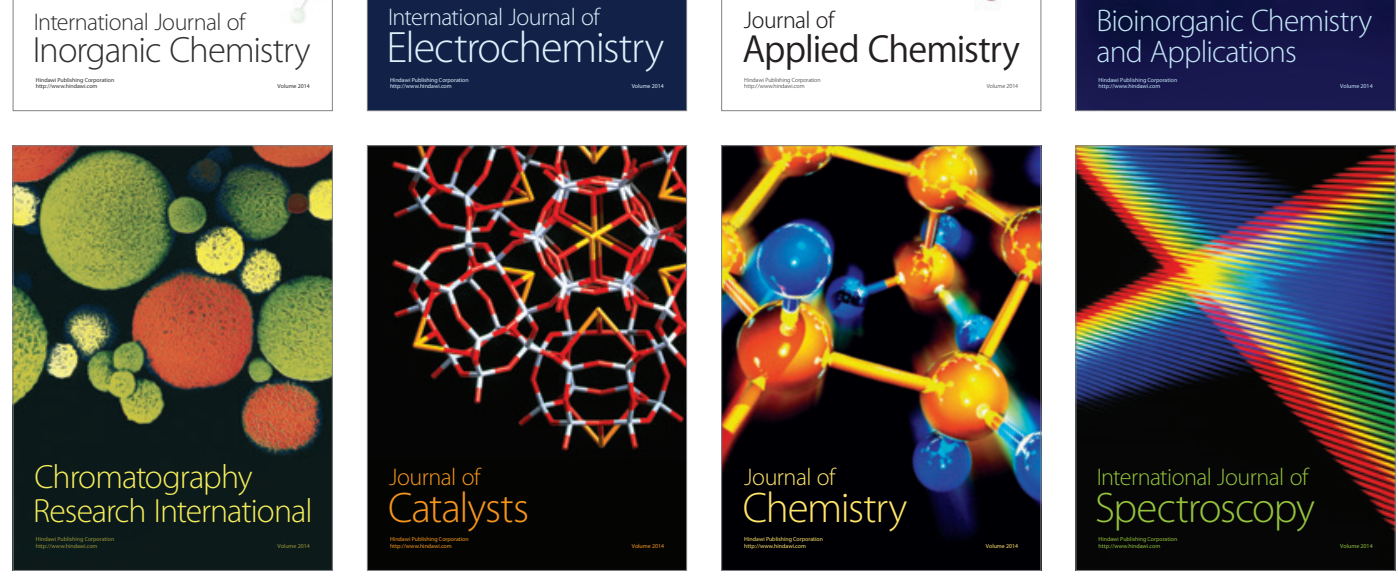